\title{
Introduction of Disaster Cognitive Psychological Science
}

\author{
Rui Nouchi1,2 \\ ${ }^{1}$ Human and Social Response Research Division, International Research Institute of Disaster Science, Tohoku \\ University, Sendai, Japan \\ ${ }^{2}$ Department of Advanced Brain Science, Smart Ageing International Research Center, Institute of \\ Development, Aging and Cancer, Tohoku University, Sendai, Japan \\ Email: rnouchi@idac.tohoku.ac.jp
}

Received 10 February 2015; accepted 12 March 2015; published 16 March 2015

Copyright (C) 2015 by author and Scientific Research Publishing Inc.

This work is licensed under the Creative Commons Attribution International License (CC BY).

http://creativecommons.org/licenses/by/4.0/

(c) (i) Open Access

\section{Abstract}

Disaster science is an academic field that explores mechanisms of disasters, investigates economic, social, and environmental impact of disasters, and develops systems for disaster prevention, mitigation, and restoration. After the 2011 Great East Japan (Tohoku) earthquake and tsunami disaster, reduction and avoidance of potential losses from disasters have received much attention. The purpose of this article is to introduce a new research field in disaster science called disaster cognitive psychological science. First, we define disasters in disaster science. Second, disaster cognitive psychological science is introduced. The scopes of disaster cognitive psychological science are 1) to clarify human mental processes and behaviors in any situation related to disasters such as evacuation behavior, risk perception, and decision making, and 2) to develop and evaluate new systems for disaster prevention, mitigation, and restoration such as education and training programs for disaster prevention. Finally, disaster cognitive psychological science research has only just begun. We shall continue our research related to disaster cognitive psychological science.

\section{Keywords}

Disaster Science, Cognitive Science, Risk Perception, Disaster Cognitive Psychological Science

\section{Introduction}

On average, about 220 natural catastrophes, 70 technological disasters and 3 new armed conflicts occur each year [1]. Disaster science is an academic field that explores mechanisms of disasters, investigates economic, social, and environmental impact of disasters, and develops systems for disaster prevention, mitigation, and resto- 
ration. After the 2011 Great East Japan (Tohoku) earthquake and tsunami disaster, reduction and avoidance of potential losses from disasters have received much attention. Although historical and literary accounts of disasters date back thousands of years, scientific analyses are more recent [2]. The purpose of this article is to introduce a new research field in disaster science, called disaster cognitive psychological science. We begin by defining disasters in disaster science. Next, disaster cognitive psychological science is introduced.

\section{Definitions of Disasters in Disaster Science}

The term “disasters” has a complex meaning. Barkun reported that disasters can be recognized more easily than defined [3]. Disasters have been assigned many different definitions depending on the research status [4]. Some researchers [5] have reported that the word “disaster” has the properties of a "sponge word”. Quartantelli [6] reported that most people working in the disaster area have avoided explicit and systematic attention to answering the question, "What is a disaster?". However, to develop the academic field of disaster science, we cannot avoid defining disasters. Consequently, we attempt to define disasters here.

It is necessary to consider the difference between hazards and disasters. A hazard is any biological, chemical, mechanical, environmental or physical agent that is reasonably likely to cause harm or damage to humans, other organisms, or the environment in the absence of its control [7] [8]. Hazards are typically classified as natural or anthropogenic hazards. Especially, natural hazards are physical events such as floods, volcanic eruptions, earthquakes, or tsunamis, which make an impact on human beings and their environments [9]. Disasters occur when hazards meet vulnerability. Vulnerability is the potential for harm or loss inherent in a person or object [10] [11]. Therefore, disasters can be evaluated using the following equation: disasters = hazards + vulnerability [12]. Disasters occur as a result of a hazard that strikes a vulnerable community or group whose inherent capacity is insufficient to withstand or cope with its adverse effects and impact. It means that the hazards are causes of disasters and that disasters are the results of hazards.

Etymologically, the word "disaster" entered the English language originally in the 16th Century from the French word "desastre”. This was composed from the prefix “des” (dis) and "astre” which was derived from the Latin word "astrum” and means star. Desastre therefore means literally "bad star", which corresponds to an astrological configuration describing an extremely unfavorable event. According to the Oxford English Dictionary (http://www.oxforddictionaries.com/definition/english/disaster?q=disaster), a disaster is "a sudden accident or a natural catastrophe that causes great damage or loss of life: an event or fact that has unfortunate consequences".

Although many different definitions of disasters exist in academic fields [4], most studies generally concur with the initial definition of disaster by Fritz. According to Fritz [13], a disaster is "an event concentrated in time and space, in which a society or one of its subdivisions undergoes physical harm and social disruption, such that all or some necessary functions of the society or subdivision are impaired”. After disasters, physical harm and social disruption (now more commonly labeled physical and social impacts) occur because the event exceeds normal limits of protection [14]. A disaster is an event (or series of events) that severely disrupts normal activities. The requirement that an event be concentrated in time and space is necessary to distinguish between disasters and other phenomena. For example, about 4000 people are killed in traffic accidents each year in Japan, but this is not regarded as a disaster in the same sense because the accident is not concentrated in time and space. Typically, disasters are classifiable into two basic groups: natural and anthropogenic. Among the natural disasters are earthquakes, volcanoes, hurricanes, floods, and fires. Among the anthropogenic disasters are war, pollution, nuclear explosions, fires, hazardous materials exposures, explosions, and transportation accidents.

Based on the previously described arguments, we defined disasters as follows. Disasters occur when hazards meet vulnerability (disasters = hazards + vulnerability). A disaster is 1) classifiable as either a natural or anthropogenic disaster, 2) an event concentrated in time and space, and 3) a phenomenon that can cause environmental, physical, and psychological damage to life and property and destroy the economic, social and cultural life of people.

\section{Introduction of Disaster Cognitive Psychological Science}

\subsection{Why We Add Disaster Cognitive Psychological Science as a New Research School in Disaster Science?}

Disaster science is a multidisciplinary academic field for the study of phenomena related to disasters and ha- 
zards. Alexander [9] proposed six distinct schools of thought and expertise related to disaster science. They can be classed broadly as geography, anthropology, sociology, development studies, health sciences and geophysical science with engineering. Although these six schools are involved in the development of disaster science, previous studies did not specifically examine human-disaster-related behaviors. Therefore, we propose that disaster cognitive psychological science, which is the combined word for psychology and cognitive science, be added as a seventh school for disaster science.

For several reasons, we add disaster cognitive psychological science as a new research school in disaster sciences. First, traditional disaster sciences did not specifically examine human-behavior-related disasters. They mainly emphasized the study of hazards and the impacts of disasters on societies and environments. Second, both psychology and cognitive science are interdisciplinary scientific studies of the mind and its processes. Therefore, psychology and cognitive science are human-centered approaches and specifically examine human behaviors. Third, psychology and cognitive science are hub sciences. Psychology is one hub science among academic fields [15]. Many sub-research fields are associated with psychology, such as clinical, educational, social, cognitive, and animal psychology. Cognitive science is a key research concept when we study human minds. Cognitive science connects artificial intelligence, linguistics, anthropology, psychology, neuroscience, philosophy, and education [16].

Additionally, there are some reasons why we created new terms such as disaster cognitive psychological science. First, we simply combined "disaster science", "psychology”, and "cognitive science”. Second, existing disaster psychology usually specifically examines the care of disaster survivors [17]. Traditional disaster psychology is not a comprehensive approach for disasters and is investigated only after the disaster phase. However, we emphasize that disaster cognitive psychological science investigates all phases of disasters such as those before, during, and after disasters. Consequently, we created the new term "disaster cognitive psychological science” and suggest that disaster cognitive psychological science be included as a main research school for disaster sciences.

\subsection{Definition of Disaster Cognitive Psychological Science}

We defined disaster cognitive psychological science as an interdisciplinary scientific study of disaster related to human mental processes, behavior, and social systems. Disaster cognitive psychological science is classifiable into basic and advanced studies. The purpose of the basic study is to clarify human mental processes and behaviors in any situation related to disasters such as evacuation behavior, risk perception, and decision making. The purpose of advanced study is to develop and evaluate new systems for disaster prevention, mitigation, and restoration such as education and training programs for disaster prevention. The basic and advanced studies are studied based on the circulation model for disaster-related behaviors. The circulation model for disaster-related behaviors includes three main phases in chronological order (pre-disaster, during-disaster, and post-disaster phases). For the pre-disaster phase, research topics include disaster education. For example, disaster education using some tool is one important study in the pre-disaster phase [18] [19]. For the during-disaster phase, risk rating and evacuation behaviors are subjects of research. For example, investigating cognitive and neural processes during risk perception is interesting theme [20]. For the post-disaster phase, we investigate the organization of volunteers, recovery processes, and effects of disasters on mental processes. For example, our recent studies demonstrated that the regional gray matter volumes in survivors of the 2011 Great East Japan (Tohoku) earthquake and tsunami disaster were smaller than that in the healthy people who did not experience the disaster [21].

\subsection{What Is the Difference between Disaster Cognitive Psychological Science and Traditional Disaster Psychology?}

As we mentioned above, disaster cognitive psychological science differs from traditional disaster psychology in that disaster cognitive science specifically examines all disaster phases comprehensively. Traditional disaster psychology has investigated only the post-disaster phase. Disaster cognitive psychological science incorporates various analytical methods such as behavioral experiments, neuroimaging methods, interviews, observations, questionnaires, computer simulation modeling, and field research. Disaster-related behaviors are extremely complicated. Therefore, we must conduct cross-disciplinary studies and use a wide range of methods to ascertain and comprehend disaster-related behaviors. 


\section{Conclusions}

Two main parts exist in this article. In the first part, we briefly reviewed the terms of disasters in disaster science. We newly defined disasters as described below. Disasters occur when hazards meet vulnerability (disasters = hazards + vulnerability). Disasters are 1) divided into natural and anthropogenic disasters, 2) events concentrated in time and space, and 3) phenomena that can cause environmental, physical, and psychological damage to life and property and destroy the economic, social, and cultural life of people.

In the second part, we proposed disaster cognitive psychological science as a new academic research field in disaster science. Disaster cognitive psychological science is an interdisciplinary scientific study of disaster-related human mental processes, behavior, and social systems. The scopes of disaster cognitive psychological science are 1) to clarify human mental processes and behaviors in any situation related to disasters such as evacuation behavior, risk perception, and decision making, and 2) to develop and evaluate new systems for disaster prevention, mitigation, and restoration such as education and training programs for disaster prevention.

In sum, disaster cognitive psychological science research has only just begun. We shall continue our research related to disaster cognitive psychological science.

\section{Acknowledgements}

We thank all colleagues at the Institute of Development, Aging, and Cancer (IDAC), at the International Research Institute of Disaster Science (IRIDeS), and at Tohoku University for their support. R.N was supported by a Grant for Special Project Research of IRIDeS (2013-B8 and 2013-A4:

http://irides.tohoku.ac.jp/topics_project//projects2013.html, http://irides.tohoku.ac.jp/topics_project/projects2014.html).

\section{References}

[1] International Federation of Red Cross and Red Crescent Societies (2001) World Disasters Report: Focus on Reducing Risk. Eurospan, London.

[2] Alexander, D.E. (2005) An Interpretation of Disaster in Terms of Changes in Culture, Society and International Relations. In: Perry, R.W. and Quarantelli, E.L., Eds., What Is a Disaster? New Answers to Old Questions, XLibris Press, Philadelphia, 25-38.

[3] Barkun, M. (1974) Disaster and the Millennium. Yale University Press, New Haven.

[4] Al-Madhari, A.F. and Keller, A.Z. (1997) Review of Disaster Definitions. Prehospital and Disaster Medicine, 12, 1721.

[5] Quarantelli, E.L. and Dynes, R.R. (1970) Editors Introduction. American Behavioral Scientist, 13, 325-330. http://dx.doi.org/10.1177/000276427001300302

[6] Quarantelli, E.L. (1985) What Is Disaster? The Need for Clarification in Definition and Conceptualization in Research. http://udspace.udel.edu/handle/19716/1119

[7] Sperber, W.H. (2001) Hazard Identification: From a Quantitative to a Qualitative Approach. Food Control, 12, 223228. http://dx.doi.org/10.1016/S0956-7135(00)00044-X

[8] Breakwell, G.M. (2007) The Psychology of Risk. Cambridge University Press, Cambridge. http://dx.doi.org/10.1017/CBO9780511819315

[9] Alexander, D.E. (1993) Natural Disasters. UCL Press, Chapman \& Hall, Routledge, London.

[10] Weichselgartner, J. (2001) Disaster Mitigation: The Concept of Vulnerability Revisited. Disaster Prevention and Management, 10, 85-94. http://dx.doi.org/10.1108/09653560110388609

[11] Cutter, S.L. (1996) Vulnerability to Environmental Hazards. Progress in Human Geography, 20, 529-539. http://dx.doi.org/10.1177/030913259602000407

[12] Blaikie, P., Cannon, T., Davis, I. and Wisner, B. (2004) At Risk-Natural Hazards, People’s Vulnerability and Disasters. 2nd Edition, Routledge, London.

[13] Fritz, C.E. (1961) Disaster. In: Merton, R.K. and Nisbet, R.A., Eds., Contemporary Social Problems, Harcourt, Brace and World, New York, 651-694.

[14] Kreps, G.A. (1983) Sociological Inquiry and Disaster Research. Annual Review of Sociology, 10, 309-330. http://dx.doi.org/10.1146/annurev.so.10.080184.001521

[15] Boyack, K.W., Klavans, R. and Börner, K. (2005) Mapping the Backbone of Science. Scientometrics, 64, 351-374. 
http://dx.doi.org/10.1007/s11192-005-0255-6

[16] Hunt, E. (1989) Cognitive Science: Definition, Status, and Questions. Annual Review of Psychology, 40, 603-662. http://dx.doi.org/10.1146/annurev.ps.40.020189.003131

[17] McCaughey, B.C. (1986) The Psychological Symptomatology of a U.S. Naval Disaster. Military Medicine, 151, 162165.

[18] Yamori, K. (2009) Action Research on Disaster Reduction Education: Building a "Community of Practice” through a Gaming Approach. Journal of Natural Disaster Science, 30, 83-96. http://dx.doi.org/10.2328/jnds.30.83

[19] Nouchi, R. and Sugiura, M. (2014) Beneficial Effects of Learning with Game-Book on Education for Disaster Prevention in Children. Journal of Disaster Research, 9, 1079-1087.

[20] Vorhold, V., Giessing, C., Wiedemann, P.M., Schutz, H., Gauggel, S. and Fink, G.R. (2007) The Neural Basis of Risk Ratings: Evidence from a Functional Magnetic Resonance Imaging (fMRI) Study. Neuropsychologia, 45, 3242-3250. http://dx.doi.org/10.1016/j.neuropsychologia.2007.06.023

[21] Sekiguchi, A., Sugiura, M., Taki, Y., Kotozaki, Y., Nouchi, R., Takeuchi, H., Araki, T., Hanawa, S., Nakagawa, S., Miyauchi, C.M., Sakuma, A. and Kawashima, R. (2013) Brain Structural Changes as Vulnerability Factors and Acquired Signs of Post-Earthquake Stress. Molecular Psychiatry, 18, 618-623. http://dx.doi.org/10.1038/mp.2012.51 